\title{
Experimental Assessment of Moisture Transfer in the Vertical Ventilated Channel
}

\author{
Tatyana Musorina ${ }^{1}$, Vyacheslav Olshevskyi ${ }^{1}$, Anastasia Ostrovaia ${ }^{1}$ and Elena Statsenko ${ }^{1,{ }^{*}}$ \\ ${ }^{1}$ Peter the Great St. Petersburg Polytechnic University, 195251 Polytechnicheskaya str. 29, \\ St.Petersburg, Russia
}

\begin{abstract}
This article considers the moisture transfer phenomenon in the vertical ventilated channel. Also the article considers innovative structures for the vertical ventilated channel.The negative factors connected with moisture accumulation and excessive moistening of a heat insulation are given. Optimum design parameters for definition of the most intensive moisture transfer are discovered: systems with and without grooved lines. Influence that existence of technological gaps (grooved lines) has on the speed of air flows in a gap is investigated. Dependence of speed on width of the ventilated gap for a design with the opened and closed grooved lines is established empirically. The dehumidification properties of the vertical ventilated channel are described, as well as dependence of mass evaporation rate on time is established. Processes of drying-out in various conditions are compared.
\end{abstract}

\section{Introduction}

Energy and resource conservation is the central focus area of modern technical policy of the Russian Federation in the construction industry. The increase of thermal insulation of the enclosure counts for a great deal in a set of measures for energy conservation. In this regard multilayered enclosure structures with the use of porous thermal insulators gained widespread in modern construction. These materials offer the increased cold-resisting properties and allow to reduce thickness and weight of the enclosure structures. At the same time the durability and service property of such structures substantially are defined by their moisture conditions.

The control of moisture level is a necessary requirement for maintenance of the internal microclimate of buildings. Well-timed definition of excessive moistening sources also allows to support an optimum work level of the structures with the ventilated gap. That allows to improve service properties of the enclosing structures and air condition systems.

When considering this point the moisture transfer phenomenon is extremely essential. It is especially actual in climate conditions of the Northwestern District and similar regions since the increased precipitation level leads to the excessive moistening of systems.

\footnotetext{
*Corresponding author: staclena@mail.ru
} 
Moisture transfer is a process of the movement of moisture which represents transfer of vacant and physically-bounded water under the influence of gravitational and sorption (molecular and capillary) forces.

Thus, quantitative calculation of moisture transfer is one of the most important in the multilayered enclosure structure designing.

This article considers influence of parameters of the ventilated airgap on air velocity speed which moisture transfer directly depends on.

\section{Literature References}

A significant contribution to the promotion of the subject "Moisture Transfer Assessment in the Vertical Ventilated Channel" was made by [1-35].

The article [1] considers the conditions under which there is a cold air filtration in the ventilated gap. The publication [2] considers features of work of building faces with and without grooved lines. In the work [6] the optimum sizes of the airgap are defined. The author of the work [10] reveals the key problems of structures with the ventilated airgap. In the text of the work [11] the moisture transfer phenomenon in disperse and porous materials is estimated. In the article [14] authors reveal adequate existence conditions of the free convection stream in the vertical conduit. The authors of the publication [23] consider issues of a natural ventilation of the vertical channel. The work [28] considers the application of the HVF Hinged Ventilated Facades) constructions in northern climate areas. The author of the work [29] investigates the wall building with the ventilated building face thermal protection taking into account a longitudinal air filtration.

\section{Setting goals and objectives}

- Influence of grooved lines on air exchange and moisture transfer in the HVF gap

- Research of the moisture transfer phenomenon in the vertical channel

- Comparison of the dehumidification properties under various conditions

\section{Materials and Methods}

The majority of the humidity testing methods are focused on reducing moisture intake into the airgap. However the imperfection of building structures leads to their excessive moistening. In this regard more and more attention is given to the moisture accumulation ability of materials and the possibility of their drying out.

Moisture evaporates while drying from a surface of the dried-up materials. At the same time there is a moisture movement from within of a surface. The heat, necessary for moisture evaporation, is transferred from environment by means of convective surface heat transfer. If the environment has the increased temperature, the material heats up when drying and there is a movement of heat in consequence of heat conductivity. Thus, the main physical phenomena of convective drying are the following:

- heat transfer from a gaseous fluid to a surface of the dried-up samples, i.e. heat transfer between a surface and the environment by means of convection;

- movement of heat from external into internal layers in consequence of heat conductivity;

- moisture evaporation from a surface of the dried-up materials - moisture exchange with the environment

- moisture movement from the central layers to a surface; it is accepted to be called moisture transfer. 
Moisture transfer is the most difficult and important of all the listed phenomena. It has significant effect on drying behavior.

Moisture transfer, i.e. moisture movement, happens under the influence of three main forces: drop of humidity, temperature drop and pressure drop of vapor-air mixture in a material.

Moisture transfer rarely happens under the influence of any of the listed mechanisms. All types of moisture transfer which can lead to emergence of the problems caused by moisture can also help when construction materials and surfaces are drying.

The saved-up experience of research of heat and moisture transfer in the enclosure structures gives the grounds to claim that a zone of the greatest moistening is the layer of a mineral wool heat insulation adjoining the gap. Therefore, the degree of water vapor saturation in the ventilated gap is defining rather than average humidity on heat insulation thickness.

One of the most important characteristics of air exchange for moisture transfer calculation is air speed in the air layer. For its definition we will consider the stylized scheme of the ventilated gap between the "hot" plane $\mathrm{y}=0$ (with $\mathrm{T}_{\mathrm{h}}=67^{\circ} \mathrm{C}$ ) and the cold plane $\mathrm{y}=\mathrm{h}$ (with $\mathrm{Tc}=23^{\circ} \mathrm{C}$ ). Heating is provided with three heating elements located throughout the height of the installation. For equal distribution of heat elements attach to a tin sheet, therefore $T_{h}=$ const. The height of a gap is equal to $L=204 \mathrm{~cm}$, and $\mathrm{L} \gg \mathrm{h}$.

While producing a facade sample we consider the temperature difference of external and internal layers proved by performance of heating systems. The model considers wall heating and heat input from it in the air layer. The external air is supposed to come into the air layer through the lower air hole. It rises through the ventilated channel and leaves through the top air holes. Air temperature increases and its relative moisture changes during the rise. At the same time moisture increases throughout the height of the layer.

While researching moisture transfer in the air layer it is necessary to know air velocity in the gap that depends on the chosen structure of the ventilated building face - with open or pressurized grooved lines.

Let us carry out an experiment. We take the speed and air temperature in the air gap depending on its width in the structure with and without grooved lines. We use thermal anemometer for measurement.

The main calculatory dependence for the average speed of the free convection stream (FCS) in the ventilated gap:

$$
\vartheta=\varphi \sqrt{1-\frac{\mathrm{T}_{\mathrm{c}}}{\mathrm{T}_{\mathrm{h}}}} \sqrt{2 \mathrm{gL}}
$$

Where $\mathrm{T}_{\mathrm{c}}$ is the temperature of a cold wall, $\mathrm{T}_{\mathrm{h}}$ is the temperature of a hot wall, $\mathrm{L}$ is the building face height, $\varphi$ is the velocity coefficient which is determined by a formula:

$$
\varphi=\frac{\vartheta}{\sqrt{2 g L\left(1-\frac{\mathrm{T}_{\mathrm{c}}}{\mathrm{T}_{\mathrm{h}}}\right)}}
$$

By results of experiment we construct the schedule of dependence on the relation of $\mathrm{L}$ to $\mathrm{h}$ where the result is presented by red color at the closed grooved lines and blue at the open grooved lines: 


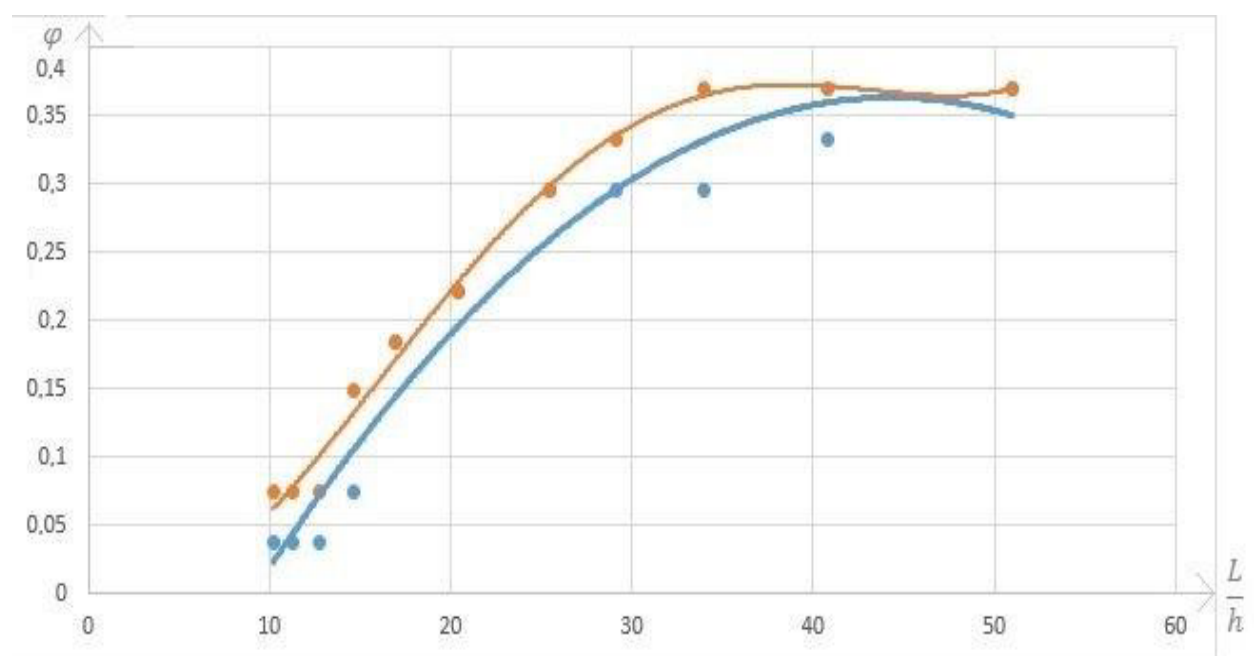

Fig. 1. Dependence $\varphi$ on L/h.

On the basis of the data available from experiments it is possible to draw the following conclusions:

- $\quad$ at great $\mathrm{L} / \mathrm{h}$ values $(\geq 25)$ the vertical ventilated gap behaves as the channel with coefficient $\varphi \leq 0,4$

- at small $\mathrm{L} / \mathrm{h}$ values $(<25)$ the vertical ventilated gap behaves as the heated plate in free-air space.

- at equal $\mathrm{L} / \mathrm{h}$ values the coefficient of velocity when the grooved lines is closed is more, than when ones are open. It testifies to higher velocity values in a structure with closed grooved lines

For simulation of the channel it is necessary to have $\mathrm{L} / \mathrm{h} \geq 25$, i.e. $h \leq \frac{L}{25} \approx 8 \mathrm{~cm}$. Thus for determination of mass evaporation rate we take a gap equal to $8 \mathrm{~cm}$ and a structure without grooved lines.

For definition of the influence of air velocity on moisture transfer it is reasonable to conduct the following experiment: to place a humidified heat insulation in the ventilated gap of a structure and to measure weight under various conditions of drying-out: in the ventilated channel and in natural environment.

For definition of air velocity influence on moisture transfer we use a mineral-cotton sample $50 \mathrm{~mm}$ thick.

The size of the sample is $95 \times 210 \times 50 \mathrm{~mm}$. The mass is $140 \mathrm{~g}$. Let us humidify the sample. The mass of the saturated sample is $154 \mathrm{~g}$.

One prototype is located in the airgap of HVF, and the identical one we will leave in natural environment. Then the time of drying-out of samples is measured and compared.

Using the obtained data we find the mass evaporation rate:

$$
m=\frac{\Delta m}{\Delta t}
$$

where $\Delta \mathrm{m}$ - the mass difference of two consecutive measurements, $\Delta \mathrm{t}$ - the interval between measurements, $\Delta \mathrm{t}=600 \mathrm{~s}$.

Mass rate of vaporization in the structure:

$$
m^{\prime}=\frac{\Delta m}{\Delta t}=\frac{14}{5100}=0.0027
$$


In natural environment: $m^{\prime}=\frac{\Delta m}{\Delta t}=\frac{6}{5100}=0.0012$.

Let us give the dependence of mass speed on each interval from the time where the result is presented by red color under natural conditions, blue - in the air gap:

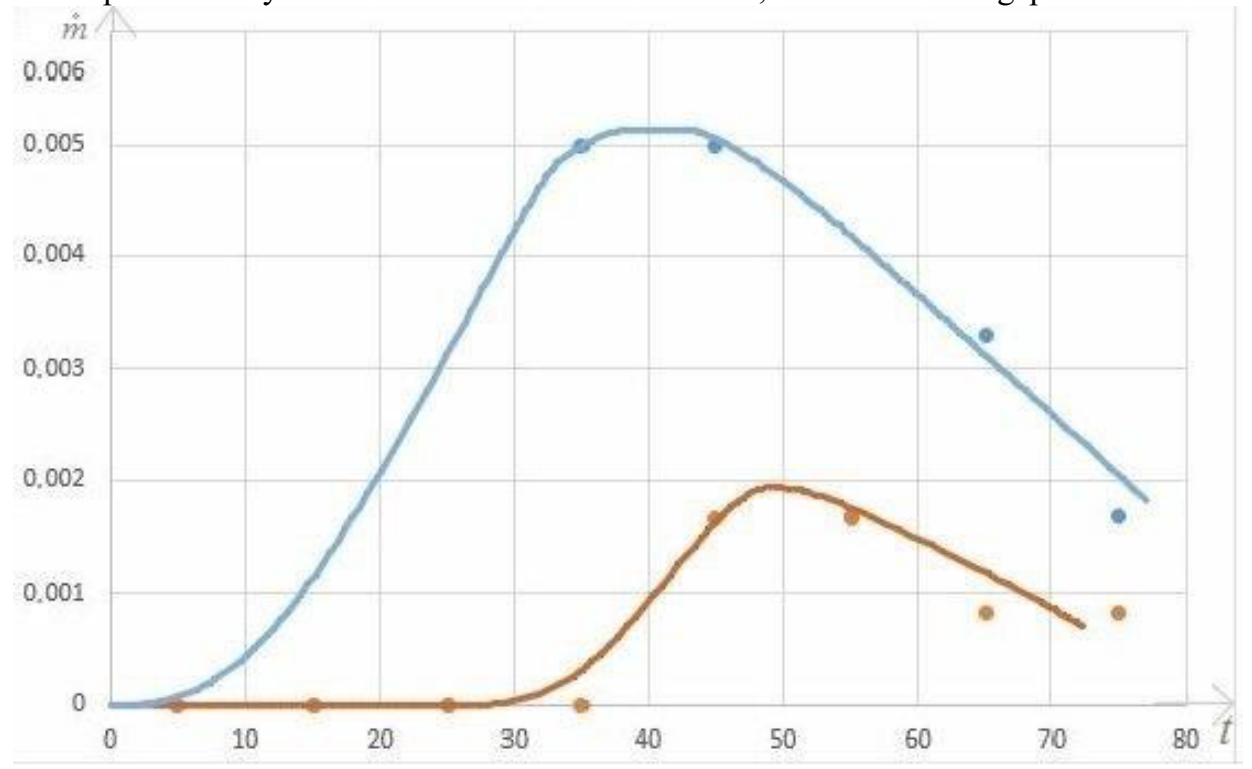

Fig. 2. Dependence of $m^{\prime}$ on $t$.

The figure shows that the hidden heat of evaporation takes place at the initial stage of time, there is no evaporation. Evaporation begins when the sample warms up to the saturation point at this pressure.

\section{Summary}

Building humidity control is a key condition of increase of their durability, effective use and a healthy microclimate. Knowing of moisture sources and moisture transfer mechanisms in buildings and in enclosure structures allows to improve design choices of buildings and ventilation systems. The strategy of humidity control must be based on this knowing.

On the ground of the experiments we draw the following conclusions:

- a structure without grooved lines represents the "ideal" gap since velocity values are hare higher in it.

- the average moisture evaporation rate from a physical model is more, than in fixed air since the saturation temperature is higher in the ventilated air gap.

\section{References}

1. V.L. Kvint, V.V Okrepilov, Herald of the Russian Academy of Sciences, 84 (3), 188 200 (2014)

2. A.F. Ostrovaja, E.A. Stacenko, V.Ja. Olshevskyi, T.A.Musorina, MATEC Web of Conferences, 53, (2016)

3. V.V Okrepilov, V.N. Krutikov, G.I. El'kin, Measurement Techniques, 57 (2),109-116 (2014) 
4. M.R. Petrichenko, Soviet research, 23, 703-715 (1991)

5. A.F. Ostrovaja, M.R. Petrichenko, E.A. Stacenko, Applied Mechanics and Materials, 725-726 (2015)

6. M.R. Petrichenko, Second Edition St. Petersburg State Polytechnical University Journal. Physics and Mathematics, 143-149 (2012)

7. M.R. Petrichenko, M. Petrichenko, E.B. Yevtushenko, Magazine of Civil Engineering, 37, 35-40 (2013)

8. V.V Okrepilov, A.Yu. Smirnov, Measurement Techniques, 56(1), 54-60 (2013)

9. V.V Okrepilov, Standarty i Kachestvo, 10, 52-55 (2005)

10. N.I. Gamajunov, S.N. Gamajunov, Vestnik TvGTU, 22, 46-54 (2012)

11. S.V. Kornienko, Inzhenerno-stroitel'nyj zhurnal, 2, 18-23 (2012)

12. V.V Okrepilov, Ivanova, G. Standarty i Kachestvo, 12, 62-68. (2004)

13. E.B. Yevtushenko, M.V. Petrochenko, Magazine of Civil Engineering, 8, 38-45 (2013)

14. V. Murgul, Procedia Engineering, 117, 808-818 (2015)

15. V.V Okrepilov, Standarty i Kachestvo, 3, 94-96. (2003)

16. V.V Okrepilov, Studies on Russian Economic Development, 24(1), 35-42 (2013)V. G. Gagarin, V. V. Kozlov, I. A. Mehnecov, AVOK, 8, 71-80 (2005)

17. J.Li, Y.Chow, Centre for Sustainable Energy Technologies (CSET), 198-203 (2014)

18. Jun Hana, Lin Lua,Jinqing Penga, Energy and Buildings, 56, 204-209 (2013)

19. V.N. Bukhartsev, M.R. Petrichenko, Power Technology and Engineering, 5, 374-377 (2011)

20. Alin V. Rosca, Ioan Pop, International Journal of Heat and Mass Transfer, 60, 355$364(2013)$

21. G. Barrios, G. Huelsz, R. Rechtman, J. Rojas, Energy and Buildings, 43, 219-223 (2011)

22. H. Yang, X. Feng, G. Xia, Q. Wan, ISHVAC, 384-396 (2013)

23. L. Gaillard, S. Giroux-Julien, C. Menezo, H. Pabiou, Chair Habitats and Energy Innovations, 54-67 (2012)

24. N. Harmati, R. Folić, Z. Magyar, J. Dražić, N. Kurtović-Folić, Thermal Science, Nuclear Institute Vinča, Belgrade (2015)

25. N. Harmati, Z. Magyar, Energy Procedia, 78, 2458 - 2463 (2015)

26. V. Pukhkal, A. Bieliatynskyi, V. Murgul, Journal of Applied Engineering Science, 14, $93-101(2016)$

27. N. Harmati, Ž. Jakšić, N. Vatin, Procedia Engineering, 117, 791 - 799 (2015)

28. N. Harmati, R. Folić, Z. Magyar, Thermal Science, 19(3), 865-880 (2015)

29. V.V. Okrepilov, V.N. Krutikov, G.I. El'kin, Measurement Techniques, 57 (2), 109116 (2014)

30. V.L. Kvint, V.V. Okrepilov, Herald of the Russian Academy of Sciences, 84 (3), 188200 (2014)

31. V. Murgul, MATEC Web of Conferences, 53, 01046 (2016)

32. A. Gorshkov, V. Murgul, O. Oliynyk, MATEC Web of Conferences, 53, 01045 (2016) 